\title{
Mental Toughness: The Importance of Psychological Preparations for Penalty Shootouts in Ice Hockey
}

\author{
Lars E. Chröisty ${ }^{1}$, Leif Janson1, Torsten Norlander ${ }^{1,2^{*}}$ \\ ${ }^{1}$ Center for Sensorimotor Research, Vestibularis Clinic, Kalmar, Sweden \\ ${ }^{2}$ Center for Research and Development, Evidens University College, Goteborg, Sweden \\ Email: *at.norlander@mailbox.tele2.se
}

How to cite this paper: Chröisty, L. E., Janson, L., \& Norlander, T. (2018). Mental Toughness: The Importance of Psychological Preparations for Penalty Shootouts in Ice Hockey. Psychology, 9, 165-178. https://doi.org/10.4236/psych.2018.92011

Received: January 10, 2018

Accepted: February 4, 2018

Published: February 7, 2018

Copyright (c) 2018 by authors and Scientific Research Publishing Inc. This work is licensed under the Creative Commons Attribution International License (CC BY 4.0).

http://creativecommons.org/licenses/by/4.0/

\section{c) (i) Open Access}

\begin{abstract}
The purpose of the current study was to investigate for the first time whether specifically targeted psychological and match-like training improves the effectiveness of shooters and goalkeepers during penalty shootouts in ice hockey. Participants were 58 male ice hockey players ( 36 shooters and 22 goalkeepers) at national elite level, representing all the teams in the Swedish Hockey League (SHL). Their average age was 27.29 years $(\mathrm{SD}=4.80)$. The shooters performed together 185 shots at shootouts during the current season, of which $62(34 \%)$ resulted in goals. Goalkeepers guarded the goal during the season against 228 shots during shootouts, of which they saved 158 (69\%). The participants were categorized into three levels in terms of preparation for shootouts: a) Low; No special preparation, b) Middle; Sporadic preparations, and c) High; Intensive psychological preparations and specific match-like training. The results for the shooters showed that the middle-level group gained more than twice goal efficiency (34.15\%) compared to the low-preparation group (15.50\%), and the high-preparation group $(70.83 \%)$, in turn, gained just over twice as much efficiency as the middle group. The goalkeeper results were somewhat less remarkable, yet showed that the high preparation group (77.81\%) had $8 \%$ better rescue efficiency compared to the low-preparation group (60.90\%). To conclude, the results of the current study suggest that it is beneficial at ice hockey elite level to carry out specially designed training as a preparatory feature for future shootouts. Future studies may show how these experiences can be applied in lower divisions and in junior leagues where nervousness and stress can be assumed to be a major negative factor.
\end{abstract}

\section{Keywords}

Ice Hockey, Mental Toughness, Shootout, Sport Psychology 


\section{Introduction}

International research shows that psychological factors such as self-esteem and stress management play a decisive role in elite sports performance (Hardy, Jones, \& Gould, 1996; Janson, Archer, \& Norlander, 2005; Mellalieu, Hanton, \& Fletcher, 2006), but also for inexperienced amateur athletes (Bergman \& Norlander, 2005). The more advanced performance in relation to the ability of an athlete or exerciser, the greater the need to develop a "mental toughness" (Jones, Hanton, \& Connaughton, 2007). Mental toughness has been defined (Jones, Hanton, \& Connaughton, 2002) as: "having the natural or developed psychological edge that enables you to, generally, cope better than your opponents with the many demands (competition, training, lifestyle) which sport places on a performer and specifically, be more consistent and better than your opponents in remaining determined, focused, confident, and in control under pressure" (p. 209).

Individual sports such as archery (Norlander, Bergman, \& Archer, 1999), where performance is to be conducted under concentration and with an audience, are particularly challenging. A study (Kim, Kim, \& So, 2015) examined how different factors affected results in Korean archery. Through qualitative methods (interviews with a large number of archery coaches) and quantitative methods (confirmatory factor analysis with 463 archers), four key success factors were identified: Skill factors, Fitness factors, Strategy factors and Psychological factors (e.g., confidence, concentration, and emotional control). In this study, it was found that the psychological factors accounted for $51.9 \%$ of the performance factors, while the factors attributable to skill ended up in second place by $32.8 \%$.

We have not found any studies that have conducted the corresponding detailed mapping of performance factors in team sports. On the other hand, there are several studies as well as well-proven experiences showing the importance of psychological factors in team sports (Longshore \& Sachs, 2015; Orlick, 2008; Schinke \& Hackfort, 2016). When the individual achievements are in focus during a match, such as when a quarterback in American football throws the ball (Petrie, Deiters, \& Harmison, 2014) or when a batman in cricket defends his wicket (Thelwell, Weston, \& Greenlees, 2007), or in penalty situations in handball (Vignais, Bideau, Craig, Brault, Multon, Delemarche, \& Kulpa, 2009), basketball (Deutscher, Frick, \& Prinz, 2013), soccer (Asamoah, \& Grobbelaar, 2016; Diment, 2014) or ice hockey (Barbour \& Orlick, 1999), it is reasonable to assume that the psychological factors in team sports are at least as important as for the individual sports.

Ice hockey is a sport where mental toughness is often emphasized as a necessary element (Westerlund, 1997). At the same time, there is a lack of studies that analyze the need for mental preparation for the most exposed positions in the sport, namely the shooter and the goalkeeper during penalty shootout. Shootout enters if there is still a draw after an overtime period. Then a number of players from each team are selected to alternately perform shots against the opposing team's goalkeeper. The team that during shootout scored most goals wins. Al- 
though there are no psychological studies directly dedicated to analyze players' preparations for penalty shootouts in ice hockey, there are both studies and experiences (Miller, 2003) that enable international and national elite team recruiters to successfully search for players with promising features.

Such features have been methodically studied and trained in the Finnish ice hockey which have certainly contributed to the fact that Finland, from being a middle team in the world championships, has developed into one of the strongest. The following characteristics were defined (Westerlund, 1997) as central to the ice hockey mental requirements: a need to achieve (i.e., willpower and stamina), positive aggressiveness (i.e., energetic and tough performance), self-confidence (i.e., positive and realistic self-esteem and a belief in their own potential), independence (i.e., being able to handle routines independently as well as ability to act in new and odd situations), ability to cope with stress (i.e., maintain or even improve the level of other qualities under pressure), dominance (i.e., to be tough in one on one situations) and emotional maturity (i.e., be able to control emotions and the affect they have on the player's actions).

The Finnish experiences are in line with studies that show that modern coaching in all sports, including team sports, must take into consideration the individual athlete's personality and development (e.g., Norlander \& Archer, 2002; Norlander, Bergman, \& Archer, 2002) in order to integrate mental and physical training in the best possible way. In ice hockey this applies especially to positions as shooters and goalkeepers (Guay, 2014). Due to the very central role of elite level goalkeepers, they usually get psychological training, which is reasonable because they are expected to be able to stop up to $90 \%$ of all shots during a match. The goalkeeper's exposed role is further illustrated by the fact that if a puck hits the goal from the blue line, i.e., from 18 meters, with a measured speed of $161 \mathrm{~km} / \mathrm{h}$, the puck reaches the goalkeeper within 0.4 seconds, which does not give him much time to block the shot (Guay, 2014). However, it is not as common for players who are usually nominated to be shooters to gain access to mental training as specific preparation for future shootouts.

In a study on timing (Janson, Archer, \& Norlander, 2003) consisting of 106 athletes from seven different sports, distributed at club level, national and international levels, the impact of nervousness and stress was analyzed on how strategic muscles during performance were mobilized and relaxed. Those who performed at international or highest national level showed lower average muscle tension immediately before the shot, hit or throw than Club level athletes. The observed pattern, during the complete action, was evidenced also immediately before $(0.1 \mathrm{sec})$ the action itself. The elite level athletes also showed lower average muscle tension immediately after the shot, hit or throw compared to lower level athletes. A follow-up qualitative study (Janson et al., 2005) with eight of Sweden's leading athletes, who throughout the years had collected gold medals from Olympic Games and World Championships, showed that athletes at the highest level learn to accept their nervousness. The eight masters told about their 
techniques to transform the stress into something that influences in a positive direction. The shooters and goalkeepers who participated in the current study were all players in the Swedish national elite teams, and there they are considered to be among the very best. Against this background, their perceived stress during shootouts is not likely not to have the negative role it can be expected to have at lower levels.

The purpose of the present study was to investigate for the first time whether attitudes to mental training and match-like preparations by shooters and goalkeepers at Swedish elite hockey level affect the effectiveness during penalty shootouts. The study had three hypotheses: a) The more intense shooters and goalkeepers train with psychological preparations and match-like techniques and tactics, the greater the efficiency can be expected in terms of goals and rescues. b) Shooters and goalkeepers who have a positive attitude towards mental training get greater efficiency in terms of goals and rescues, and c) Perceived stress during shootouts by elite hockey players is not associated with the effectiveness of shooters or goalkeepers.

\section{Methods: Shooters}

\subsection{Participants}

The study involved 36 male hockey players ( 35 forwards and 1 back), all of which belonged to the teams who play in the Swedish Hockey League (SHL) and who by their respective coaches were selected as shooters at shootouts, i.e., whenever a match in the playoff ended as a draw and according to rules must be settled by penalty shootout. Their average age was 27.94 years $(S D=5.18)$. Four of the participants were hockey-educated in North America, two in Norway and the remaining 30 in Sweden. Of the players 21 used a left-hand grip on the club shaft and 15 a right-hand grip. Independent Samples $t$-test (5\% level) showed no significant differences between left or right handed grips regarding age, number of shots or number of goals scored ( $p s>0.05$ ).

\subsection{Instruments}

Goal efficiency. By compiling statistics of the shooters' results in SHL after a seasons completed penalty shootouts, a measure of the number of shots and number of achieved goals was obtained. The shooters' goal making effectivity was defined as the percentage of goals scored on the total number of shots. Together they had 185 shots during the current season, of which 62 (34\%) resulted in goals.

Perceived stress. Participants assessed on a visual analog scale (VAS) how they used to experience stress just before a shot. The scale went from 0 ("No experienced stress") to 10 ("Very intensely experienced stress"). The shooters scored an average of 4.36 ( $S D=2.58)$.

Attitude to mental training. Participants were interviewed about their attitude towards mental training. The answers were categorized to those who were 
skeptical or did not consider mental training as helpful (skeptical, $n=21$ ) and those who considered mental training to be of significant importance (positive, $n$ $=15$ ). The categorization was made by two of the authors who first evaluated the material individually, then jointly compared their solutions (which were noticeably similar), and finally agreed on the distribution.

Preparations for shootouts. Participants were also interviewed as to the extent and manner in which they were prepared for shootouts. Categorization took place according to a similar procedure as described above. It then emerged that the participants could be divided into three groups. Those who indicated low preparation $(n=12)$ had hardly ever prepared themselves. Those who described mid-level preparation $(n=18)$ trained shootouts sporadically. Finally, those who had high preparation $(n=6)$ did intensively train shootouts with psychological preparations (retrieval) and specific match-like training in techniques and tactics.

\subsection{Procedure}

All 14 teams participating in the Swedish Hockey League (SHL) were included in the study with the stated purpose to evaluate and raise the quality of penalty shootouts. Immediately after each home game for one of the teams from Stockholm, one of the shooters was interviewed as well as one from the opponent team. The interviews took place in a quiet and delimited corner in the respective dressing rooms. Before that, each team's coach had according to a random procedure asked one of the players who used to be commissioned as a shooter if he wanted to participate in the study. The coach also informed that participation in the study was completely voluntary. Before the interview was conducted, it was once again clarified that participation was entirely voluntary and that the interviewee was entitled to interrupt participation at any time and without having to motivate. Furthermore, the respondent was guaranteed confidential treatment and complete anonymity when the results were published. After that, the participant responded to interview questions following a pre-established semi-structural interview guide (Kvale \& Brinkman, 2009). In addition to questions about age, position in the team, perceived stress and more, the interview questions mainly focused on attitudes to mental training and to what extent and in what way the participant was prepared for penalty shootouts. During the interviews, the player's response was recorded to provide a basis for both a quantitative study (the current study) and a planned future qualitative study. Following the interviews, the respondents were informed that they would have access to the results when they were in writing.

\section{Methods: Goalkeepers}

\subsection{Participants}

In the study, 22 male hockey goalkeepers participated, all of whom belonged to at least one of the 14 teams who play in the Swedish Hockey League (SHL), and 
who were chosen by their respective coaches to be net minders under shootout. Their average age was 26.23 years $(S D=3.98)$ and their average length was $185.82 \mathrm{~cm}(S D=5.07)$. Hockey goalkeepers are often categorized according to three styles (techniques): (a) Stand Up, the goalkeeper is high up with the body and uses club and pick glove to save shots; (b) Butterfly, the goalkeeper plays with a low center of gravity to quickly reach both knees while pushing his feet against each post; (c) Hybrid, the goalkeeper does not go down as often as in butterfly but also selects other less common rescue movements. In the current study, five participants used Stand Up, two Butterflies and fifteen Hybrids. Kruskal-Wallis Test (5\% level) showed no significant differences between different goalkeeper styles in terms of age, number of penalties or number of rescues $(p s>0.05)$. However, in regard to length there was a possible trend ( $p=$ $0.07)$ and a subsequent test (Jonckheere trend test, $5 \%$ level) showed a significant effect $(J=40, p=0.040)$ : Butterfly $(M=180.00 \mathrm{~cm})$, Hybrid $(M=185.33 \mathrm{~cm})$, and Stand Up $(M=189.60 \mathrm{~cm})$.

\subsection{Instruments}

Rescue efficiency. By compiling statistics of the goalkeepers' results in SHL after a season's penalty shootouts, measurements were obtained of the total number of penalties and the number of rescues saved. Goalkeepers' effectiveness was defined as percent saving on the number of penalties. Together they had guarded the goal during the season against 228 shots of which they saved 158 (69\%).

Perceived stress. Participants assessed on a visual analog scale (VAS) how they used to experience stress just before a shot. The scale went from 0 ("No experienced stress") to 10 ("Very intensely experienced stress"). The goalkeepers scored an average of $4.69(S D=1.26)$.

Attitude to mental training. Participants were interviewed about their attitude towards mental training. The answers were categorized similarly as described for the shooters to those who were skeptical or did not consider mental training or co-operation with mental coach as helpful (skeptical, $n=11$ ) and those who felt that mental training through the support of a mental coach was significant (positive, $n=11$ ).

Preparations for shootouts. Participants were also interviewed as to the extent and manner in which they were prepared for shootouts. It was then found that the participants could be categorized, according to the procedure already described, in three groups. Those who indicated low preparation $(n=7)$ had hardly ever prepared themselves. Those who described mid-level preparation ( $n$ =6) trained shootouts sporadically. Finally, those who had high preparation ( $n=$ 9) did intensively train shootouts with psychological preparations (retrieval) and specific match-like training in techniques and tactics.

\subsection{Procedure}

The procedure followed the same model as for the shooters. 


\section{Methods: Ethical Considerations}

This study followed the ethical standards of the World Medical Association declaration of Helsinki concerning Ethical Principles of Medical Research Involving Human Subjects. In addition, the elite ice hockey teams participated in the study as private organizations in order to get an outside evaluation of their operations, thus giving their players the opportunity to freely express their views without having to consider officials or coaches. Given these conditions, in accordance with the Swedish rules on ethics, the material contained in the report can be used to compile an article.

\section{Results: Shooters}

\subsection{Attitude to Mental Training}

Perceived stress. Independents Samples t-test was used to investigate whether shooters' experienced stress during shootouts could be linked to attitudes to mental training. Dependent variable was Perceived Stress and independent variable was Attitude (skeptical, positive). The analysis showed no difference ( $p>$ 0.05 ) between skeptical and positive attitudes to mental training in terms of perceived stress. For mean values and standard deviations see Table 1.

Goal efficiency. Independents Samples t-test with Goal Efficiency as dependent variable and Attitude (skeptical, positive) as independent variable showed $[t(34)=-4.12, p<0.001]$ that shooters with positive attitude to mental training had higher goal making efficiency compared to those who had a skeptical attitude. For mean values and standard deviations see Table 1.

\subsection{Preparations for Shootouts}

Perceived stress. A one-way ANOVA was used to investigate whether participants' perceived stress during shootouts could be linked to their degree of preparation for shootouts. Dependent variable was Perceived Stress and independent variable was Preparations (low, middle, high). The analysis showed no differences $(p>0.05)$ in terms of perceived stress between different degrees of preparation. For mean values and standard deviations see Table 2.

Goal efficiency. A one-way ANOVA with Goal Efficiency as dependent variable and Preparations (low, middle, high) as independent variable showed $[F(2$, $35)=17.48, p<0.001]$ a significant effect. A post hoc test (Tukey HSD, 5\% level)

Table 1. Shooters' attitudes toward mental training (skeptical and positive) in terms of number of players $(N)$, mean $(M)$, and standard deviations $(S D)$ for perceived stress and goal effectiveness at shootouts.

\begin{tabular}{ccccccc}
\hline & \multicolumn{3}{c}{ Skeptical } & \multicolumn{3}{c}{ Positive } \\
\hline & $N$ & $M$ & $S D$ & $N$ & $M$ & $S D$ \\
\hline Perceived stress & 21 & 3.83 & 2.01 & 15 & 5.10 & 2.88 \\
Goal effectiveness & 21 & 21.50 & 25.02 & 15 & 51.61 & 15.49 \\
\hline
\end{tabular}

Note: Significant difference between groups is market $\left(^{*}\right)$. 
showed that the group with high degree of preparation had significantly higher goal making efficacy compared to both the intermediate group and the low-level group. The middle group in turn had a significantly higher degree of preparation compared with the low preparation group. For mean values and standard deviations see Table 2.

\subsection{Correlations}

In order to study possible relationships between perceived stress, age and goal efficiency, a correlation analysis (Pearson's $r$ ) was conducted which did not yield any significant results $(p s>0.05)$.

\section{Results: Goalkeepers}

\subsection{Attitude to Mental Training}

Perceived stress. Independents Samples $t$-test was used to investigate whether goalkeepers' experienced stress during shootouts could be linked to attitudes to mental training. Dependent variable was Perceived Stress and independent variable was Attitude (skeptical, positive). The analysis showed no difference ( $p>$ 0.05 ) between skeptical and positive attitudes to mental training in terms of experienced stress. For mean values and standard deviations see Table 3.

Rescue efficiency. Independents Samples $t$-test was used to investigate whether attitude to mental training influenced the goalkeepers' effectiveness to make rescues at shootouts. Dependent variable was Rescue Efficiency and independent variable was Attitude (skeptical, positive). The analysis showed no difference $(p>0.05)$ between skeptical and positive attitudes to mental training in terms of rescue efficiency. For mean values and standard deviations see Table 3.

Table 2. Shooters' preparation for shootouts (Low, Middle and High) in terms of number of players $(\mathrm{N})$, mean $(M)$ and standard deviations $(S D)$ experienced stress and effectiveness at shootouts.

\begin{tabular}{cccccccccc}
\hline & \multicolumn{3}{c}{ Low } & \multicolumn{3}{c}{ Middle } & \multicolumn{3}{c}{ High } \\
\hline & $N$ & $M$ & $S D$ & $N$ & $M$ & $S D$ & $N$ & $M$ & $S D$ \\
\hline Perceived stress & 12 & 4.04 & 2.62 & 18 & 4.44 & 2.10 & 6 & 4.75 & 3.42 \\
Goal effectiveness*** & 12 & 15.50 & 17.86 & 18 & 34.15 & 19.85 & 6 & 70.83 & 16.46 \\
\hline
\end{tabular}

Note: Significant differences between all three groups are market ${ }^{(* *)}$.

Table 3. Goalkeepers' attitudes to mental training (skeptical and positive) in terms of number of players $(N)$, mean $(M)$ and standard deviations $(S D)$ for perceived stress and effectiveness at shootouts.

\begin{tabular}{ccccccc}
\hline & \multicolumn{3}{c}{ Skeptical } & \multicolumn{3}{c}{ Positive } \\
\hline & $N$ & $M$ & $S D$ & $N$ & $M$ & $S D$ \\
\hline Perceived stress & 11 & 4.73 & 1.37 & 11 & 4.64 & 1.21 \\
Rescue effectiveness & 11 & 73.66 & 13.86 & 11 & 64.75 & 5.86 \\
\hline
\end{tabular}


Table 4. Goalkeepers' preparation for shootouts (Low, Middle and High) in terms of number of players $(\mathrm{N})$, mean $(M)$ and standard deviations $(S D)$ experienced stress and effectiveness at shootouts.

\begin{tabular}{cccccccccc}
\hline & \multicolumn{3}{c}{ Low } & \multicolumn{4}{c}{ Middle } & \multicolumn{3}{c}{ High } \\
\hline & $\mathrm{N}$ & $\mathrm{M}$ & $\mathrm{SD}$ & $\mathrm{N}$ & $\mathrm{M}$ & $\mathrm{SD}$ & $\mathrm{N}$ & $\mathrm{M}$ & $\mathrm{SD}$ \\
\hline Perceived stress & 7 & 4.50 & 1.47 & 6 & 4.67 & 0.98 & 9 & 4.83 & 1.37 \\
Rescue effectiveness & 7 & 60.90 & 3.45 & 6 & 66.00 & 8.92 & 9 & 77.81 & 11.29 \\
\hline
\end{tabular}

Note: Significant difference between Low and High groups is market $\left(^{*}\right)$.

\subsection{Preparations for Shootouts}

Perceived stress. A one-way ANOVA was used to investigate whether the goalkeepers' experienced stress during shootouts could be linked to their degree of preparation for shootouts. Dependent variable was Perceived Stress and independent variable was Preparations (low, middle, high). The analysis showed no differences $(p>0.05)$ in terms of perceived stress between different degrees of preparation Table 4.

Rescue efficiency. A one-way ANOVA with Rescue Efficiency as dependent variable and Preparations (low, medium, high) as independent variable showed $[F(2,21)=7.72, p=0.004]$ a significant effect. A post hoc test (Tukey-HSD, 5\% level) showed that the high degree of preparation had significantly higher rescue efficiency $(M=77.81, S D=11.29)$ compared to the low-level group $(M=60.90$, $S D=3.45$ ), while the middle group ended up in the middle and without any significant differences to the other two groups. For mean values and standard deviations see Table 4.

\subsection{Correlations}

In order to study possible relationships between perceived stress, age and rescue efficiency, a correlation analysis (Pearson's $r$ ) was conducted which did not yield any significant results $(p s>0.05)$.

\section{Results: Comparisons between Shooters and Goalkeepers}

Statistical analyzes showed (Independent Samples $t$-test) no significant differences between shooters and goalkeepers in terms of age or perceived stress ( $p s>$ 0.05 ) and neither (Mann-Whitney $U$-test) in terms of degree of preparation ( $p>$ 0.05). Finally, statistics with Chi-Square (Fisher's Exact Test) showed no significant relationships $(p>0.05)$ between attitude to mental training and whether the participant was a shooter or a goalkeeper. Since the two efficiency measures (goal-efficiency and rescue-efficiency) assessed completely different types of performances, no statistical comparison was made between them.

\section{Discussion}

This study had three hypotheses, namely: a) The more intense shooters and goalkeepers train with psychological preparations and match-like techniques 
and tactics, the greater the efficiency can be expected in terms of goals and rescues. b) Shooters and goalkeepers who have a positive attitude towards mental training get greater efficiency in terms of goals and rescues, and c) Perceived stress during shootouts by elite hockey players is not associated with the effectiveness of shooters or goalkeepers.

For the first time, it was investigated whether shooters and goalkeepers at the elite level are preparing themselves in order to achieve increased mental toughness for forthcoming penalty shootouts. Key components in mental toughness are "remaining determined, focused, confident, and in control under pressure" (Jones et al., 2002) in order to maintain or even improve the level of different qualities under stress (Westerlund, 1997). The first hypothesis was tested by dividing both shooters and goalkeepers into three categories, namely those who indicated low or no preparations, those who described mid-level preparations and only trained shootouts sporadically, and finally those who had high preparations with intensively trained shootouts with psychological preparations integrated with specific match-like training in techniques and tactics.

For the shooters, the effects of the integrated training seemed dramatic. The middle level group gained over twice as much goal efficiency compared to the low-preparation group. Likewise the high-preparation group in turn gained more than twice as much goal efficiency as the intermediary group. Finally, the high-preparation group gained 4.5 times higher efficiency compared to the low-preparation group! It is thus obvious that it would be successful for the national ice hockey teams to put more emphasis on special designed training for the players who are involved in shootouts. Several of the shooters seemed to have insight into this as evidenced by the fact that those players who had a positive attitude towards mental training also had a significantly higher goal efficiency compared with skeptics. Even for goalkeepers it was clear that an intense match-like training integrated with psychological preparations had effect but the difference between the low-level group and the high-level group was not as dramatic. The reason for this is probably that the goalkeepers in their normal training already have features that are reminiscent of shootout. However, the high preparation group still had $8 \%$ better rescue efficiency compared to the lowpreparation group. In a shootout, that improvement can be crucial, indicating the importance of well performed preparations for shootouts also for the goalkeepers.

Shooters with a positive attitude towards mental training had better goal making efficiency compared to skeptical shooters according to the second hypothesis but attitude to mental training did not affect the goalkeeper's rescue rate. An explanation might be that the role of the goalkeeper involves participating in continuous exercises to counter or block shots and where mental training components are integrated in a natural way. Therefore they probably don't experience a need for enhanced mental training prior to shootouts. In order to motivate goalkeepers for increased efforts in preparation for shootouts, it 
may be of importance that they receive information about results showing differences between groups with high and low levels of preparation.

The third hypothesis stipulated that perceived stress during shootouts by elite hockey players is not associated with the effectiveness of shooters (goals) or goalkeepers (rescues) which was confirmed by the results of the correlation analyzes between perceived stress and effectiveness measurements (goals and rescues). These results were further supported by the fact that either attitudes to mental training or preparations for shootouts influenced the perceived stress. This is in line with definitions of the concept of mental toughness for athletes at the elite level (Jones et al., 2002). It is also in line with a phenomenological study where eight prominent Swedish athletes at the highest international level were interviewed (Janson et al., 2005). It was found that they experienced stress and nervousness before and during significant competitions. Typical statements from respondents were "Long before the competition I was very nervous and went around worrying but after the competition it was hard to understand why I was so nervous", "I know that when I've got a bit into the competition I'm so nervous that it feels bad, but it works anyway", and "nervousness and fear of failure are feelings within me".

At the elite level, the point is not to try to get rid of nervousness but instead to handle it in order to maintain or even improve the level of different qualities under stress (Westerlund, 1997). The nervousness then becomes a positive energy that strengthens the focus on the competition without interfering with timing in performance (Janson et al., 2003). It is against this background that psychological factors are regarded as one of the most important performance factors in elite sports (Kim et al., 2015). Shooters and goalkeepers in the Swedish National League (SHL) have probably learned, through experience and training, to handle stress in an essentially adequate way. Thus, the improvements shown in the present study were not caused by decreased stress but of improvements of the level of different qualities such as confidence, concentration, and emotional control.

An unexpected outcome in the current study was that different goalkeeper styles could be related to length. Discussions for and against different styles have been brought and are still being carried out with great intensity, even though it has recently emerged an increasingly growing insight of being pragmatic instead of focusing on what style is best (Dillon, 2016). However, we have not previously seen that different goalkeeper styles may be linked to length as in the current study: Butterfly $(\mathrm{M}=180.00 \mathrm{~cm})$, Hybrid $(\mathrm{M}=185.33 \mathrm{~cm})$, and Stand $\mathrm{Up}(\mathrm{M}=$ $189.60 \mathrm{~cm}$ ). If the Butterfly is most suitable for the shortest, Stand Up for the longest and Hybrid for those between cannot be determined by this study due to only two participants were included in the Butterfly condition and five in the Stand Up condition. However, it is worth mentioning the observation so that future studies can investigate whether there is a link or not between length and style. A further notion is that ice hockey requires an outstanding balance ability 
(Han, Anson, Waddington, Adams, \& Liu, 2015) which is particularly important in situations that require attention and concentration (Hrysomallis, 2011) as in shootouts. Therefore further studies are also suggested to investigate the role of sensorimotor maturity (Niklasson, Rasmussen, Niklasson, \& Norlander, 2015; Niklasson, Norlander, Niklasson, \& Rasmussen, 2017).

To conclude, the results of the current study suggest that, according to the first hypothesis, it is beneficial for the ice hockey elite level teams to implement intensive integrated psychological training as a preparatory feature for future shootouts. Future studies may show how these experiences can be applied in lower divisions and in junior leagues where nervousness and stress can be assumed to be a major negative factor.

\section{Acknowledgements}

All authors had contributed substantially to the design performance, analysis and reporting of the work. The authors thank the participants for taking the time to participate in the study.

\section{Conflict of Interest}

The authors confirm that this article content has no conflicts of interest.

\section{References}

Asamoah, B., \& Grobbelaar, H. W. (2016). Positional Comparisons of Mental Toughness, Psychological Skills and Group Cohesion among Soccer Players: Sport Psychology. African Journal for Physical Activity and Health Sciences, 22, 747-759.

Barbour, S., \& Orlick, T. (1999). Mental Skills of National Hockey League Players. Journal of Excellence, 2, 16-36.

https://www.researchgate.net/publication/265238562_Mental_Skills_of_National_Hoc key_League_Players

Bergman, A., \& Norlander, T. (2005). "Hay Sacks Anonymous": Living in the Shadow of the Unidentified. Psychological Aspects of Physical Inactivity from a Phenomenological Perspective. The Qualitative Report, 10, 795-816. http://nsuworks.nova.edu/cgi/viewcontent.cgi?article=1833\&context=tqr

Deutscher, C., Frick, B., \& Prinz, J. (2013). Performance under Pressure: Estimating the Returns to Mental Strength in Professional Basketball. European Sport Management Quarterly, 13, 216-231. https://doi.org/10.1080/16184742.2012.742122

Dillon, B. (2016). The Downs and Ups of Different Goaltending Styles. A Look into the Evolution of the Net Minder Position. Ontario Hockey Association. http://www.omha.net/news_article/show/631894?referrer_id=1063069

Diment, G. M. (2014). Mental Toughness in Soccer: A Behavioral Analysis. Journal of Sport Behavior, 37, 317.

Guay, E. (2014). Creating a Goaltending Development Manual for Belgium Ice Hockey. Helsinki, Finland: Haaga-Helia University of Applied Sciences.

Han, J., Anson, J., Waddington, G., Adams, R., \& Liu, Y. (2015). The Role of Ankle Proprioception for Balance Control in Relation to Sports Performance and Injury. BioMed Research International, 2015, Article ID 842804. http://doi.org/10.1155/2015/842804

Hardy, L., Jones, G., \& Gould, D. (1996). Understanding Psychological Preparation for 
Sport. Theory and Practice of Elite Performers. Chichester, UK: Wiley.

Hrysomallis, C. (2011). Balance Ability and Athletic Performance. Sports Medicine, 4, 221-232. https://www.ncbi.nlm.nih.gov/pubmed/21395364 https://doi.org/10.2165/11538560-000000000-00000

Janson, L., Archer, T., \& Norlander, T. (2003). Timing in Sports Performance: Psychophysiological Analysis of Technique in Male and Female Athletes. Athletic Insight, 5, 1-12. http://www.athleticinsight.com/Vol5Iss4/Timing.htm

Janson, L., Archer, T., \& Norlander, T. (2005). The Achievement of Timing at the Highest Competitive Level: The Necessity of a "Driving" Concept. Athletic Insight, 7. http://www.athleticinsight.com/Vol7Iss2/AchievementofTiming.htm

Jones, D., Hanton, S., \& Connaughton, D. (2007). A Framework of Mental Toughness in the World's Best Performers. The Sport Psychologist, 21, 243-264. https://doi.org/10.1123/tsp.21.2.243

Jones, G., Hanton, S., \& Connaughton, D. (2002). What Is This Thing Called Mental Toughness? An Investigation of Elite Sport Performers. Journal of Applied Sport Psychology, 14, 205-218. https://doi.org/10.1080/10413200290103509

Kim, H. B., Kim, S. H., \& So, W. Y. (2015). The Relative Importance of Performance Factors in Korean Archery. Journal of Strength \& Conditioning Research, 29, 1211-1219. https://doi.org/10.1519/JSC.0000000000000687

Kvale, S., \& Brinkman, S. (2009). Den kvalitativa for skningsintervjun [The Qualitative Research Interview]. Lund: Studentlitteratur.

Longshore, K., \& Sachs, M. (2015). Mindfulness Training for Coaches: A Mixed-Method Exploratory Study. Journal of Clinical Sport Psychology, 9, 116-137. https://doi.org/10.1123/jcsp.2014-0038

Mellalieu, S. D., Hanton, S., \& Fletcher, D. (2006). A Competitive Anxiety Review: Recent Directions in Sport Psychology Research. In S. Hanton, \& S. D. Mellalieu (Eds.), Literature Reviews in Sport Psychology (pp. 1-45). Hauppauge, NY: Nova Science.

Miller, S. (2003). Hockey Tough. Champaign, IL: Human Kinetics.

Niklasson, M., Norlander, T., Niklasson, I., \& Rasmussen, P. (2017). Catching-Up: Children with Developmental Coordination Disorder Compared to Healthy Children before and after Sensorimotor Therapy. PLoS ONE, 12, e0186126.

http://journals.plos.org/plosone/article?id=10.1371/journal.pone.0186126 https://doi.org/10.1371/journal.pone.0186126

Niklasson, M., Rasmussen, P., Niklasson, I., \& Norlander, T. (2015). Adults with Sensorimotor Disorders: Enhanced Physiological and Psychological Development following Specific Sensorimotor Training. Frontiers in Psychology, 6, 480.

https://www.frontiersin.org/articles/10.3389/fpsyg.2015.00480/full https://doi.org/10.3389/fpsyg.2015.00480

Norlander, T., \& Archer, T. (2002). Predicting Performance Outcome in Ski and Swim Championships: Effectiveness of Mood, Perceived Exertion and Dispositional Optimism. Perceptual and Motor Skills, 94, 153-164.

https://doi.org/10.2466/pms.2002.94.1.153

Norlander, T., Bergman, H., \& Archer, T. (1999). Primary Process in Competitive Archery Performance: Effects of Flotation REST. Journal of Applied Sport Psychology, 11, 194-209. https://doi.org/10.1080/10413209908404200

Norlander, T., Bergman, H., \& Archer, T. (2002). Relative Constancy of Personality Characteristics and Efficacy of a 12-Month Training Program in Facilitating Coping Strategies. Social Behavior and Personality, 30, 773-784.

https://doi.org/10.2224/sbp.2002.30.8.773 
Orlick, T. (2008). In Pursuit of Excellence. How to Win in Sport and Life trough Mental Training. Champaign, IL: Human Kinetics.

Petrie, T. A., Deiters, J., \& Harmison, R. J. (2014). Mental Toughness, Social Support, and Athletic Identity: Moderators of the Life Stress-Injury Relationship in Collegiate Football Players. Sport, Exercise, and Performance Psychology, 3, 13-27. https://doi.org/10.1037/a0032698

Schinke, R. J., \& Hackfort, D. (2016). Psychology in Professional Sports and the Performing Arts: Challenges and Strategies. New York, NY: Routledge.

Thelwell, R. C., Weston, N. J. V., \& Greenlees, I. A. (2007). Batting on a Sticky Wicket: Identifying Sources of Stress and Associated Coping Strategies for Professional Cricket Batsmen. Psychology of Sport and Exercise, 8, 219-232.

https://doi.org/10.1016/j.psychsport.2006.04.002

Vignais, N., Bideau, B., Craig, C., Brault, S., Multon, F., Delemarche, P., \& Kulpa, R. (2009). Does the Level of Graphical Detail of a Virtual Handball Thrower Influence a Goalkeeper's Motor Response? Journal of Sports Sciences and Medicine, 8, 501-508. https://www.ncbi.nlm.nih.gov/pmc/articles/PMC3761546/

Westerlund, E. (1997). Jääkiekko [Ice Hockey]. In A. Mero, A. Nummela, K. L. Keskinen, \& M. Auvinen (Eds.), Nykyaikainenurheiluvalmennus [Modern Coaching in Sports] (pp. 527-544). Jyväskylä, Finland: Mero Oy. 